\title{
The Artistic State of Ancient Chinese Classical Poetry*
}

\author{
Yang Qingcun \\ Shanghai Jiao Tong University
}

The "poetry" is the spiritual and artistic creation of human during historical practice and civilization development, as well as a kind of literary style with both refined and popular tastes, strong flavor of life, wide range of dissemination, and strong vitality of art. While, "Ci”, as one of the poetry types with strong national characteristics, has always been enjoying the same reputation as "poetry" in the history of Chinese literature development.

In the long history of the development of human civilization, a large number of nations and countries in the world, each with its own native language and passion for life, have created brilliant poems of different historical environments and different artistic styles, which not only may be used for self-entertainment but also are widely spread. China, as one of the five human civilization cradles and the world's only place with five thousand years of uninterrupted civilization history, its achievements in poetry, no matter the world's longest heroic Epic of King Gesar ${ }^{1}$ created by historical ethnic group, or the popular scenery lyric poetry from the individuals such as Spring Dawn by Meng Haoran, Thoughts in a Quiet Night by Li Bai, A View of Taishan by $\mathrm{Du} \mathrm{Fu}$, or Anchoring at Guazhou by Wang Anshi, all fully display the artistic state of poetic creation.

The Chinese nation is known for its diligence, wisdom, love of life and creativity. After five thousand years $^{2}$ of civilization evolution, cultural development, literary tradition and poetry creation, it has forged a great country and kingdom of poetry standing firm in the east of the world. In particular, the classical poetry created in the Chinese language is the essence of Chinese culture and literature and art. As the artistic crystal of Chinese people's living practice, emotional exchange, expression of thoughts and creation of wisdom, these classical poems have long been the artistic works in the treasure house of human culture, and have been exerting more and more extensive and profound influences in the world.

It is the historical responsibility of the era to cherish the extremely precious cultural heritage and spiritual wealth of Chinese classical poetry and to develop, apply and carry forward the excellent national cultural tradition. Discussing the artistic state of ancient Chinese classical poetry is an important way to discuss the cultural inheritance, literary appreciation, artistic aesthetics and laws, as well as the necessary process of

\footnotetext{
* Fund program: This article is funded by the program titled "world-class universities and first-class subjects", a school-level program of Shanghai Jiao Tong University.

Author profile: Yang Qingcun, Doctor of Literature, Specially-appointed Professor, has issued more than one hundred articles in Social Science of China and Literary Review. etc., such as New Comments on Creation and Concepts of Prose, Exploration and Innovation of Genre Styles of Prose in Song Dynasty, etc, and published over ten masterpieces like Research on Prose of Song Dynasty, Huang Tingjian and the Culture of Song Dynasty, and Essay on Chinese Culture, etc.

Email: yangqcun@126.com Mobile: 13701759467.

${ }^{1}$ Epic of King Gesar is a heroic epic collectively created by Tibetan people. It has been orally transmitted for over 1,000 years in folk Tibetan, and now is collected into a book. It has more than 120 parts, over 1,000,000 lines, and 20 million words, and is the longest epic in the world. Please refer to China Tibetan Information Center: The Longest Epic in the World.

${ }^{2}$ Henan Jiahu site proves that the Chinese civilization boasts of over 9,000 years of history. Experts hold the view that Jiahu Culture is the first cultural relics of dating record, being the "first threshold for human kind to enter from obscuration to civilization”, as well as an important milestone in music history.
} 
interpreting, understanding and inventing the ideological content and artistic expression of works, and discovering, exploring and summarizing the laws of literary creation and artistic expression.

The ancients believed "the four elements of poets, i.e., temperament, language, rhythm and contents"3, that's to say, temperament is the root of poet, language the carrier of expression, rhythm embodies graceful forms, and ideological contents determine the artistic value. It is because "poetry move people firstly by feelings, from the language, between the rhythm, and for the profound meanings" ${ }^{4}$. Therefore, "feelings, language, rhythm and meaning” become the four most fundamental and important elements of poetic creation as well as significant standards for the appreciation of works. It is with these four elements and various means of expression and artistic means that the poet creates colorful, varied and ever-changing poems. Ancient Chinese poems, especially those classical and famous ones that have been read and passed on through the ages, also embody distinctive national characteristics in temperament, language, form, connotation, artistic conception and state.

Strong temperament is an important feature of the artistic state of ancient Chinese classical poetry. The poet is to express feelings, while the article to record things, and it is the cultural tradition of ancient China. Temperament is the most important and basic function of poetry. It is the inner soul, flowing blood and fresh life of poetry works. Therefore, Lu Ji's "Wen Fu" said "the poetry is aesthetic because of its feelings". The poem moves and influences people with its feelings. Passion produces fine poems, while indignation makes poets. Only the true, deep and sentimental feelings can move, touch, inspire and educate people. Ancient Chinese poetry classics are full of strong, deep, and sincere feelings, for example, the interrogation and condemning to unfair social phenomena in A Woodcutter's Song and Large Rat of Classic of Poetry, the lingering grief and indignation in Li Sao (The Lament) for difficulty in realizing the ideal of serving the country and worrying about the state affairs, and the sorrow and solemnness in National Martyr for mourning the soldiers who sacrificed their lives for the country. The Nineteen Ancient Poems is a reflection of integrated feelings and natural settings, honored as "deep feelings between short lines”; the Yuefu poems of Han dynasties "all are created from specific scenes and feelings"; create poem for special matter" ${ }^{\prime \prime}$ essentially to write poem with the tact of expressing feelings by specific matter. Although the so-called "feeling is based on specific matter" is aimed at "observing political situation", its ultimate purpose is to "reveal human feelings" Returning to My Farm, Libai’s joy and delight in Trip to Jiangling, Dufu's patriotic feelings in Springwatch, Mengjiao's gratitude to maternal love in Homesick Song, and Sushi's overwhelming mourning for his deceased wife in Jiang Cheng Zi-Ten Years Have We Been Parted, Xin Qiji's strong desire for national reunification and deep indignation over his unrealized aspiration in Po Zheng Zi Appreciate Sword When I Get Drunk, and Lu You's deep concern for recovering the central plains and rejuvenating the country in To My Son ...... All these poems express persistent love for the country, the nation, the society, the family and the life, and constitute strong emotional shock to the hearts of readers.

\footnotetext{
3 Bai Juyi: Letter to Yuanjiu

4 The same as above.

${ }^{5}$ Hanshu $\cdot$ Yiwenzhi

${ }^{6}$ Bai Juyi: Letter to Yuanjiu

7 The same as above
} 
Language proficiency is another important feature of the artistic state of ancient Chinese classical poetry. If literature is the art of language, then poetry is even more demanding, because poetry language is the most concise, the most exquisite, the most expressive and the most intelligent language. Throughout the history of Chinese poetry, although there are various artistic styles, and the creation of poets, especially the creation of literati, all "try to depict the scene and pursue novelty in words" ${ }^{\prime 8}$. They are very particular about wording, thus forming a rich and colorful poetry art wonder of fine language. Especially the ancient Chinese poetry classics, their language is not only vivid and distinctive but also concise and powerful, leading people to endless aftertastes. The Tang poetry "A bosom friend afar brings a distant land near” (Bidding Deputy Magistrate Du Farewell by Wang Bo) use discussion to describe soul-to-soul friendship that is beyond the distance; "Peach Flower Pool a thousand feet deep is shallower than the love of Wang Lun who sees me off" (Presented to Wang Lun by Li Bai) uses exaggeration and metaphor to describe deep friendship, which is vivid and gives people lingering taste; The poem "A smoke hangs straight on the desert vast, A sun sits round on the endless stream" (from On a Mission Towards the Frontiers by Wang Wei) depicts a giant ink painting with vast open state, clear lines, sharp edges, and dignified and powerful words. The Fairy Poet Li Bai "the both the wind and rain are surprised when Li Bai finishes writing, while the ghosts and gods are moved to tears when seeing his poem" (from Poem Sent to Li Bai by Du Fu, the Poem Saint Du Fu "My hobby is to write poems, and I won't give up if I fail to write something amazing” (Du Fu's Narration of His Own Creative Experience). Both of them have written many famous poems. The poem "Down it cascades a sheer three thousand feet, as if the Silver River were falling from Heaven" (from Watching the Lu Mountain Falls by Li Bai) describes a majestic and solemn giant painting; The poem "the portals of the rich reek of flesh and wine while frozen bodies lie by the roadside" (Du Fu: A Poem Made during the Way from Chang'an to Fengxian County) reveals the extreme disparity between the rich and the poor by striking contrast, which is soul-stirring and penetrating. The $\mathrm{Ci}$ of Song Dynasty "beside the misty green willows the morning chill is light, on the apricot blossoms, the spirit of spring has burst forth a glorious sight” (Song Qi: The Apricot Blossoms) depicts the scenery of spring by combining the objective scenery and subjective feelings closely together. "The word 'burst forth' is very vivid" (Wang Guowei: Comments on Chinese Ci Poems); The poem "outside the railings are sad chrysanthemums, over the dew are weeping orchids" (Yan Shu: Butterflies Lingering over Flowers) empathize with the object to express sorrowful feelings; the poem "gradually far away from home, and my sadness is getting thicker, just like the unceasing spring water" (Ou Yangxiu: Treading on Grass) uses widening spatial distance to express more overwhelming grief of parting. The poet Li Qingzhao uses "flourishing leaves and withering flowers" (Like a Dream) to depict begonia after rain, and her poem "delicate than the yellow flowers" (Young Bird) compares the image of chrysanthemum with the skinny protagonist, to implicitly convey her deep missing of family members.

Formal beauty is the third feature of the artistic state of ancient Chinese classical poetry. Content determines form, and form serves content; Form is not only the carrier of content, but also an integral part of content. Apart from the content and music factors, the reason why Chinese classical poetry has the lasting and vigorous artistic vitality and the great charm of frequent reading is that it is flexible, diverse and relatively fixed in genre form, which is also an important reason that cannot be ignored. The free and unrestrained ancient long poems mostly have excellent contents, such as Southeast the Peacock Flies, Moonlit River in Spring and

${ }^{8}$ Liu Xie: The Literary Mind and the Carving of Dragons · The Poetry of Ming Dynasty. 
Everlasting Regret, etc. The poems with strict rhythm and Ci for singing especially show the formal beauty of poetry. Metrical poetry makes full use of and gives full play to the irreplaceable characteristics of Chinese language and characters in pronunciation, tone, rhyme, antithesis, understanding and other aspects. With short sentence patterns and stable metrical patterns, the works are rich in strong music elements and strong language rhythm, as well as vivid artistic images and exciting emotions. For instance, Du Fu's famous seven-character verse "Two golden orioles sing amid the willows green, a row of white egrets flies into the blue sky. My window frames the snow-crowned western mountain scene, my door oft says to eastward-going ships 'Goodbye!' uses numeral, quantifier, noun, verb as well as dynamic animals, static scene, and location antithesis to create a beautiful artistic conception with distinct layers, bright colors and fresh pictures. Su Shi Rain After Drinking on the Lake: "Shimmering water at its full, sunny day best, blurred mountains in a haze marvelous even in rain. Compare West Lake to the beautiful woman $\mathrm{Xi} \mathrm{Zi,} \mathrm{she} \mathrm{looks} \mathrm{just} \mathrm{as} \mathrm{becoming} \mathrm{lightly}$ made up or richly adored.” The first two sentences are neat and orderly, while the remaining two are smooth and novel. One more example, the Slow Slow Song by Li Qingzhao tactfully uses the characteristics of Chinese pronunciation and the effect of reproducing Chinese characters to express the sad feelings of breaking up the country and mourning the death of her husband, which has been appreciated by people throughout the ages.

Deep connotation is the fourth characteristic of the artistic state of ancient Chinese classical poetry. In ancient China, poetry was taught as "gentle and honest" ${ }^{\text {, }}$ which is the artistic principle and basic requirement of poetry creation. It is also an important principle that integrates personality cultivation with artistic accomplishment, and integrates subject matter with social effect. Under the guidance of this theory, implication, deep euphemism, avoiding shallow and straight, avoiding vulgar, creating artistic conception, and paying attention to the feelings, become the mainstream of Chinese classical poetry. At the same time, the Chinese ancient poetry are not only rich in content, extensive in theme, "euphemistic" as the orthodox school in art technique, but also blend in life folk custom, realistic thinking, historical allusion, myths and legends, proverbs and allusions, etc, to show the profound national cultural accumulation and ideological connotation and create a broad space for readers to understand the content and imagine the art. For example, $A$ Wonderful Night in Spring by Wang Ruoxu of Tang Dynasty expresses deep parting thoughts by depicting graceful natural scene and implies the philosophy of eternal time, limitless space and tiny individual; Ode to Mounting Youzhou's Terrace by Chen Zi'ang "No ancients before me, Nor comers from behind. Reflecting on the infinite of heaven and earth, alone, in a sadness sublime, and tears come.” Although there are only four sentences, the poem contains penetrating thoughts on cosmic concept and ambitions; The Stork Tower by Wang Zhihuan "exhausting my eyes to a thousand li further, I am ascending one more storey of the tower" implies motivation while depicting the scenery; Du Fu's "three officials" and "three departures" express his deep sympathy to the common people and pondering on social reality. "Recapture of the Regions North and South of the Yellow River" reveals the poet's intense patriotic feelings from the unrestrained and passionate lines ...... More examples, the "why can't tell the true shape of Lushan” (Written on the Wall at West Forest Temple), "the river is warming, which the ducks are first to know" (Inscription on Huichong's Painting of a Spring River) by Su Shi of Song Dynasty, “mountains multiply, streams double back - I doubt there’s even a road; willows cluster darkly, blossoms shine-another village ahead” (A Trip to Mountain West Village) by Lu You, "how could it be so clear and cool? For fresh water comes from the source" (The Book) by Zhu Xi, and so on, all contain rich

${ }^{9}$ The Book of Rites · Interpretation of Classics. 
meanings and are given richer and fresher ideological contents by readers of later generations. Moreover, the use of allusion is very common in ancient poetry. As allusions have been spread for a long time and formed fixed meanings, they have rich cultural connotations. Proper use of them can not only save words, but also enhance implicitness and increase information. For example, Li Shangyin uses "great minds think alike", "Lantai”, "Pengshan", "blue bird" and so on in No Title, Fan Zhongyan uses the story of Later Han Dynasty The Legend of Dou Xian in Fisherman's Pride, Su Shi uses the story of Records of the Three Kingdoms The Legend of Zhou Yu in The Charms of Niannu, Qin Guan uses the legend of the Weaver Girl and the Cowherd in The Seventh Night of the Seventh Moon, Xin Qiji uses a series of allusions like Records of the Grand Historian The Legend of Lian Po and Lin Xiangru, Sun Quan of the Three Kingdoms, Sung Dynasty Emperor Liu Yu of the Southern Dynasties in Joy of Eternal Union, etc., all these are very popular. The application of allusions greatly enriches the cultural connotation of poetry, and also enables national traditional culture to be preserved and spread during historical development.

Novel artistic conception is the fifth characteristic of the artistic state of ancient Chinese classical poetry. The poetry emphasize not only temperament but also artistic conception, which is a kind of artistic effect by perfect combination of ideological contents and artistic presentation technique. Creativity and novelty is an important goal pursued by literary creation. The poetry express temperament which is reflected in picture. It is the picture that makes the poetry vivid, and it is creativity and novelty that makes the poetry attractive and shocking. Ancient Chinese poetry take emotion, scene, matter, reason, meaning and interest as the main creative elements, and their main goal is to express mood, present life, reflect the society, and embody the age. The poet often flexibly applies various artistic presentation techniques to closely combine the objective scene and subjective feelings, to integrate emotion, scenery, matter and reason, and thus creates vivid artistic conception of deep emotions. For example, Wang Wei's poem An Autumn Night in the Mountain "through the green pines the bright moon shines, over the smooth stones the clear spring flows" conveys from the beautiful picture his love for quiet mountain, He Zhizhang's poem The Willow "emerald fashioned into a tall tree, hung with myriad silk braids of green” expresses the poet’s love for spring via the graceful willow; Li Bai's poem $A$ Visit to Sky-Mother Mountain in a Dream "midway, I saw the sun rise from the sea, heard the Cock of Heaven crow", "growls of bears and snarls of dragons", "sun and moon gleaming” describes magnificent scenery; Cen Shen's poem Song of White Snow on Secretary Wu's Return to Capital "as though a gust of spring wind swept past overnight, bringing thousands upon thousands of pear trees into bloom” uses peculiar imagination and vivid metaphor, leaving the readers strong novelty and beautiful picture.

State is the sixth characteristic of the artistic state of ancient Chinese classical poetry. The state is the comprehensive embodiment of the author's ideological height and artistic power, and also an important symbol to measure the artistic achievement of poetry. If artistic conception is to convey thoughts and feelings through images, then the state is more reflected in the height of thoughts and art. The basic orientation of ancient

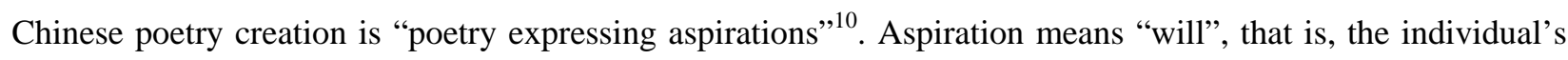
feelings, thoughts and wishes. The ancient theory of "poetry expressing ambition" leads poetry to a creative path full of positive significance. Thus, expressing the ideal of serving and making contributions to the country, praising integrity, fairness and justice, expressing patriotic emotion and love for the people and life, expressing love to nature and freedom, demonstrating the indignation for unrealized aspiration, attack or derogation of

\footnotetext{
${ }^{10}$ Shang Shu Yu Shu.
} 
malpractices, and disapproval and criticism of atrocities, and so on, are becoming the main contents and important subjects of poetry creation; The ideological concepts and value orientations such as "people-oriented", "the unity of heaven and man", "big economy for the common people" and "good administration and stability" also enhance the ideological state of poetry works. The acclaimed poets and creative masters of ancient China, such as Qu Yuan, Li Bai, Du Fu, Bai Juyi, Su Shi, Lu You, Xin Qiji and so on, all blend their pondering on natural universe, mankind existence, national safety, social development, and real life, as well as on the contradiction between human and nature, human and society, man to man, and human beings and themselves, and on life road of "taking the nation's rise and fall as one's own duty", ambitions and aspirations, and social reality, etc. into the poetry, to make them assume magnificent and shocking vision as well as enlightening and penetrating state, and to demonstrate the poets' noble character, profound knowledge and broad mind.

In a word, the ancient Chinese poetry, especially classical masterpiece, is the essence of Chinese traditional culture. Due to the sincere feelings, beautiful artistic conception, fine rhyme, and readability, they have always been favored by the people, not only being an important part of the language teaching material, but also a part of people's cultural life. The recipients and the creator are exchanging ideas and communicating with each other across historical time and space, savoring the beauty of the ideas and artistic conception of the works, enjoying the impact of emotions and the baptism of art, and feeling the broadness and profoundness of the excellent national traditional culture. At the same time, they also receive the influence and nourishment of culture and art imperceptibly. Consciously or unconsciously, the works cultivates literary taste, cultural accomplishment and civilized temperament, as well as image thinking ability and artistic creativity.

\section{References}

Epic of King Gesar, please refer to China Tibetan Information Center: The Longest Epic in the World.

Bai Juyi: Letter to Yuanjiu

Hanshu Yiwenzhi

Liu Xie: The Literary Mind and the Carving of Dragons The Poetry of Ming Dynasty

The Book of Rites Interpretation of Classics

Shang Shu Yu Shu 